\title{
'Magical' developments in paediatric dentistry explored
}

This year's British Society of Paediatric Dentistry's (BSPD's) annual conference drew such a crowd that an overflow lecture theatre was made available to delegates.

Held in Leeds on 12-15 September, paediatric dentists in attendance acquired new perspectives on the treatment of immature traumatised teeth and the care of children with amelogenesis imperfecta.

A session on regenerative endodontics and dental pulp tissue engineering was particularly popular. Hosted by Professor Monty Duggal, the panel included Professors Alastair Sloan and Jacques Nor, both leading names worldwide in the field of tissue engineering, and Drs Jinn Tong and Hani Nazzal, who have both undertaken research in the field of regenerative endodontics.

Among the key points to emerge were:

- There should be a move away from calcium hydroxide apexification for immature teeth

- MTA is the gold standard for the moment but more evidence is needed to support its use in the long-term

- Regenerative endodontic treatment (RET) has emerged for the treatment of immature teeth with short roots in order to achieve root development and thickening of the dentinal walls - but results are not yet predictable

- There is still no perfect solution for the immature traumatised tooth - but with the advent of dental pulp cell engineering there may be in the future.

Also at the conference, Zoe Marshman presented her new cognitive-based therapy resource to help reduce anxiety in children and young people needing dental treatment; and delegates learned why the commissioning guide for paediatric dentistry services has not moved forward. Professor Sara Hurley, Chief Dental Officer for England and keynote speaker at the conference, explained that there

\section{Think Tank held in Manchester}

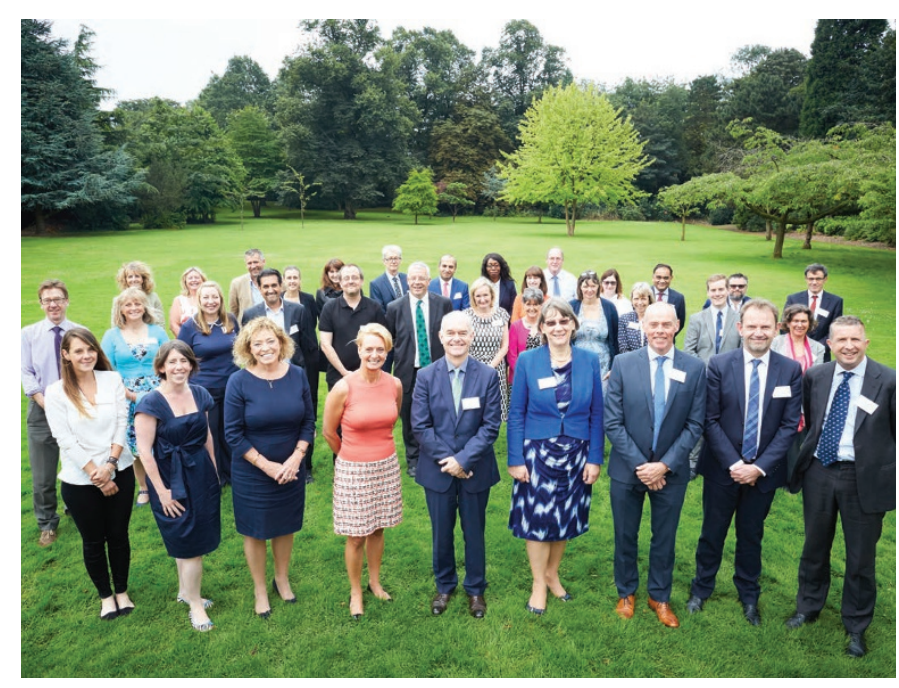

The Manchester University Dental School hosted an 'Oral Health \& Dental Care Policy Research Think Tank' in August. This inaugural event was an initiative of Sara Hurley, Chief Dental Officer England, but also attended by the Chief Dental Officers for Wales, Scotland, Northern Ireland and their teams, to bring together academic and policy collaboration.

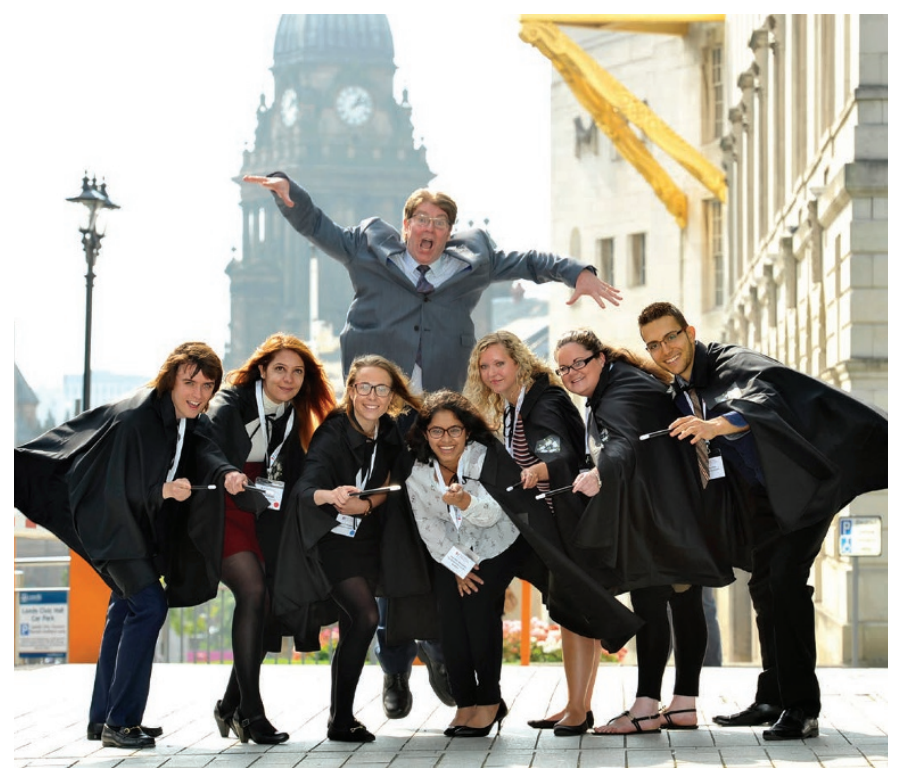

has been a moratorium on all the commissioning guides with the exception of those that had already been approved, and that she hopes to work with BSPD to roll out a commissioning guide.

Stephen Fayle, the Chair of the BSPD commissioning group, delivered a passionate presentation, providing his perspective on commissioning and the priorities for the profession. He told Professor Hurley: 'BSPD is open for business'.

The theme of the conference was 'The Magic of Paediatric Dentistry, Conjuring up Solutions' and this was reflected in the forward-looking presentations as well as themed social events (pictured).

www.bspd.co.uk

\section{Dragons' Den for dentists?}

Do you have an idea for research which you would like to get off the ground? Or perhaps you are already running a study which you wish to expand or extend?

As the leading UK dental journal, the $B D J$ is always keen to promote dental research. To further facilitate collaboration between dental researchers, general dental practitioners, dental industry and funding bodies, we are introducing a new space in the Upfront section of the BDJ entitled: 'Calls for collaboration'.

We invite you to send your requests for collaboration to us for this section and we will publish these to help you to find assistance among the wider dental community.

Please send any 'Calls for collaboration' to BDJ News Editor, Kate Quinlan by email to k.quinlan@nature.com. You should briefly (max. 300 words) describe your research and what type of collaboration you are seeking. 